\title{
The effect of ethoxylate nonionic surfactants on phase inversion temperature and salinity: an alternative approach for vegetable oil recovery from spent bleaching earth
}

\author{
Gitsada Panumonwatee ${ }^{1}$, Ampira Charoensaeng ${ }^{2}$ and Noulkamol Arpornpong1,* \\ ${ }^{1}$ Faculty of Agriculture, Natural Resources and Environment, Naresuan University, Thailand. \\ ${ }^{2}$ Petroleum and Petrochemical College, Chulalongkorn University, Thailand.
}

\begin{abstract}
An accurate determination of the hydrophilic-lipophilic nature of surfactants plays an important role in guiding microemulsion formation. The objective of this study is to determine the effect of ethoxylate numbers (EONs) (3, 5, and 7 moles) of nonionic surfactants on a phase inversion temperature (PIT) and optimum salinity based on the equivalent alkane carbon numbers (ACNs) of vegetable oils. Three vegetable oils, soybean oil, crude rice bran oil and crude palm oil, were selected for use as a surrogate oil to represent the residual oils found in spent bleaching earth. In this study, the hydrophilic-lipophilic deviation (HLD) was used to predict the optimum salinity $\left(0-20 \% \mathrm{wt}\right.$.) at various temperatures $\left(25-55^{\circ} \mathrm{C}\right)$. The results showed that the ACNs of crude rice bran oil, crude palm oil, and soybean oil were $15.41 \pm 0.35,13.71 \pm 0.41$, and $17.60 \pm 0.28$, respectively. In comparison, these predictions with the experimental results, the data showed slight deviations in the optimum salinity with the specific temperature. Finally, the ACN and the surfactant characteristics obtained in this study were combined with the HLD equation and used to validate its practically and utility for guiding the optimum microemulsion formulation.
\end{abstract}

\section{Introduction}

The Bleaching step in the refinery edible oil process operates using bleaching earth as an adsorbent for removing undesirable matters (e.g., colour pigments, phosphatides free fatty acids, or gums). Spent bleaching earth (SBE) containing a high fraction of residual vegetable oil approximately $20-40 \mathrm{wt} . \%$ is discarded waste [1]. It is classified as industrial waste by the federal regulation (DIW Waste Code, 0203 99, Thailand) and required to have proper treatments prior its disposal [2].

One of the alternative approaches for enhancing vegetable oil's recovery from spent bleaching earth through the application of microemulsification technology using microemulsion-based washing agent. Microemulsions (ME) consisting of four types (Winsor Type I, II, III, and IV) are isotropic liquid mixtures of surfactant-water-oil [3]. At low salinity concentration or low temperature, hydrophilic surfactants can selfaggregate to form normal micelles, also called Winsor Type I microemulsion. As the salinity and temperature are increased (more hydrophobicity), phase transition can shift from Type I to Type III and then to Type II [3, 4]. Regarding the Winsor Type III microemulsion, bicontinuous micelles can be obtained when the interfacial tension (IFT) between water and oil is balanced, resulting in the lowest IFT [4].

Recently, the hydrophilic-lipophilic deviation (HLD) concept has been applied to design optimum formulation of microemulsion-based washing agents. It also includes the parameters of the oil polarity, temperature ranges, salinity concentrations, alcohol levels, and surfactant hydrophobicity. The detail of HLD can be seen elsewhere [5-7]. For nonionic surfactants, the temperature is a key parameter for determining microemulsion phase transition. The microemulsion phase transition from Type I to III can occur once the system reaches the phase inversion temperature (PIT).

Arpornpong et al. [8] formulated microemulsionbased washing agent to enhance rice bran oil recovery from SBE using HLD concept. The HLD equation predicted a Winsor type III microemulsion $(\mathrm{HLD}=0)$ at an optimum condition of $10 \% \quad \mathrm{v} / \mathrm{v}$ Dehydol LS3TH/crude rice bran oil system with $8.5 \%$ wt. $\mathrm{NaCl}$ at $25^{\circ} \mathrm{C}$. As compared to the experimental phase behavior, the result showed that an optimum condition of $10 \% \mathrm{v} / \mathrm{v}$ Dehydol LS3TH/crude rice bran oil system with $15 \%$ wt. $\mathrm{NaCl}$ at $25^{\circ} \mathrm{C}$ showed the highest oil extraction efficiency for up to $71.38 \pm 1.75 \%$.

However, there are several types of crude vegetable oils (e.g., palm oil, rice bran oil, soybean oil) remaining in SBE. The residual oils in SBE depends on the raw materials used to make purified oil in vegetable oil industries. Each oil has its own hydrophobicity which is similar to the equivalent alkane carbon number ( $\mathrm{ACN})$. The ACN was initially introduced by Cash et al. [9]. Even though the ACN of general oils such as $n$-alkanes have been reported, the regional or specific oils for industrial application still requires further detailed

\footnotetext{
* Corresponding author: noulkamola@nu.ac.th (N. Arpornpong).
} 
research. The ACN of each oil has often been determined by studying the microemulsion phase behaviour. This procedure seems to be far more complex for the operator who oversees several types of oils, surfactants, or other additives. As a result, the HLD concept could potentially be used as a guide for selecting the optimum formulation of microemulsion-based washing agent for removing vegetable oil in SBE.

The aims of this study are (1) to determine the alkane carbon number $(\mathrm{ACNs})$ of three vegetable oils, (2) to study the effect of the ethoxylate oxide groups on fatty alcohol ethoxylate surfactant (EONs) on phase inversion temperature (PIT) and salinity, and (3) to compare the phase behaviour study results with the HLD predicted data.

\section{Materials and Methods}

\subsection{Materials}

Three fatty alcohol ethoxylate nonionic surfactants which share the same carbon chain length (C12-14) with 3,5 , and 7 ethylene oxide (EO) groups were used as in this research and received from the Thai ethoxylate Co., Ltd (Thailand). The surfactant properties are shown in Table 1.

Vegetable oils used as a surrogate residual oil in SBE were crude rice bran oil, crude palm oil and soybean oil. The crude rice bran oil and crude palm oil that were used was receive from the Surin Bran oil Co., Ltd. and the Suksomboon palm oil Co., Ltd., respectively. The soybean oil was purchased from the Morakot Industries.

Four alkane hydrocarbons, hexane (C6, 99\%), decane (C10, 99\%), dodecane (C12, 99\%) and hexadecane (C16, 99\%) were purchased from the Acros Organics. Their ACN values are 6, 10, 12 and 16, respectively [9].

Table 1. The properties of the surfactants.

\begin{tabular}{clllll}
\hline \multicolumn{1}{c}{ Name } & \multicolumn{1}{c}{ Formula } & MW $^{\mathrm{a}} \mathrm{HLB}^{\mathrm{b}}$ & $\begin{array}{c}\text { Cloud } \\
\text { point }\left({ }^{\circ} \mathrm{C}\right)\end{array}$ \\
\hline Dehydol LS3 TH & $\mathrm{C}_{12-14}\left(\mathrm{C}_{2} \mathrm{H}_{4} \mathrm{O}\right)_{3}$ & 318 & 7.9 & $51-53$ \\
& $\mathrm{OH}$ & & & \\
Dehydol LS5 TH & $\mathrm{C}_{12-14}\left(\mathrm{C}_{2} \mathrm{H}_{4} \mathrm{O}\right)_{5}$ & 406 & 10.3 & $68-73$ \\
& $\mathrm{OH}^{\mathrm{OH}}$ & & & \\
Dehydol LS7 TH & $\mathrm{C}_{12-14}\left(\mathrm{C}_{2} \mathrm{H}_{4} \mathrm{O}\right)_{7}$ & 494 & 12.1 & $52-58$ \\
& $\mathrm{OH}$ & & & \\
\hline
\end{tabular}

${ }^{a}$ MW is the molecular weight $(\mathrm{g} / \mathrm{mol})$ providing by the manufacturer.

${ }^{\mathrm{b}}$ HLB is the hydrophilic-lipophilic balance providing by the manufacturer

\subsection{Methods}

\subsubsection{Determination of the vegetable oil ACN}

The alkane carbon number of oil (ACN) is a key parameter for determining the hydrophilic-lipophilic balance of surfactants. In order to determine the ACN value, the HLD equation for nonionic surfactant system must be simplified by way of the operating microemulsion system without $\mathrm{NaCl}$ and alcohol while adjusting the temperature up until the phase inversion temperature point (PIT) has been reached. The HLD equation for nonionic surfactant systems was shown in Eq. $1[6,10]$.

$$
H L D=\beta+b(S)-k(A C N)-f(A)+c T \Delta T
$$

Where $\beta$ is the surfactant characteristic value, $b$ is the electrolyte constant $(0.13$ for $\mathrm{NaCl}), \mathrm{S}$ is the salinity concentration $(\mathrm{g} / 100 \mathrm{ml}), \mathrm{k}$ is the constant of the surfactant $(0.17$ is normal $), \mathrm{f}(\mathrm{A})$ is the concentration of alcohol, cT which is a temperature coefficient is $0.06 \mathrm{~K}$ 1 and $\Delta \mathrm{T}$ is a different temperature between the studied and the reference temperature $\left(25^{\circ} \mathrm{C}\right)$. At equilibrium of the hydrophilic potential and the lipophilic potential, the middle phase will appear (known as Winsor type III) and result in a minimum interfacial tension between water and oil in the system and HLD being equal zero.

Phase inversion temperatures was studied in flat bottom test tubes with screw caps. An equal volume of the water phase and oil phase $(5 \mathrm{ml})$ were added into a test tube and kept in a thermostatic water bath. The surfactant concentration used was $10 \% \mathrm{v} / \mathrm{v}$ in the distilled water (a non-salinity system). The PITs of known ACNs of oils including hexane (C6), decane (C10), dodecane (C12) and hexadecane (C16) were measured and used to determine the unknown ACNs of vegetable oils.

\subsubsection{Effect of EON on PIT study}

The EON in surfactant showed a hydrophilic potential. In this study, the effect of EON on PIT of individual oils studied in this experiment was determined by plotting a linear regression between EON and PIT. Three surfactants which have different numbers of polyethoxylated group $(\mathrm{EON}=3,5$ and 7$)$ were mixed with each hydrocarbon oil.

\subsubsection{Determination of optimum salinity using HLD}

The theoretical PIT point from HLD equation was obtained by using the Eq.2. The surfactant characteristic parameter $(\beta)$ can be estimated by calculating the lipophilic potential of surfactant $(\alpha)$ minus a number of polyethylene mole (EON): $\alpha$-EON. The $\alpha$ parameter was evaluated by assessing the alkyl carbon chain of surfactant, namely SACN. Salager et al. [11] found a linear regression between $\alpha$ and SACN for alcohol ethoxylate surfactant as shown is Eq.3.

$$
\alpha=0.34 S A C N+2.00
$$

After the ACN of vegetable oil was studied (section 2.2.1), the $\beta$ value of each surfactant was determined by using the Eq.2. The $\beta$ value was used for prediction of optimum salinity $\left(\mathrm{S}^{*}\right)$. The $\mathrm{S}^{*}$ was found by microemulsion phase behaviour method. A 1:1 ratio of water phase (surfactant-water- $\mathrm{NaCl}$ ) and crude palm oil was mixed to reached equilibrium. The experimental- 
based $\mathrm{S}^{*}$ and theoretical-based $\mathrm{S}^{*}$ were compared for an estimation errors.

\section{Results and discussions}

\subsection{Determination of the ACN of vegetable oils}

The ACN of vegetable oils were determined by measuring the temperature $\left({ }^{\circ} \mathrm{C}\right)$ at an optimum phase transition (Winsor Type I to III). All surfactant-oil systems were conducted at the system of $10 \% \mathrm{v} / \mathrm{v}$ surfactant/vegetable oil. The PIT was plotted as a function of the alkane carbon number $(\mathrm{ACN})$, as shown in Fig. 1.

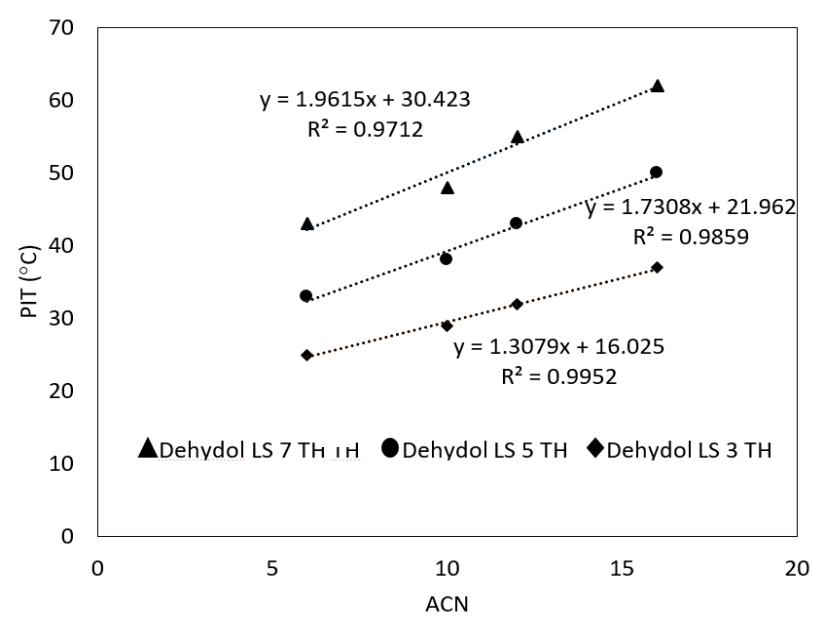

Fig.1 A plot of the phase inversion temperature (PIT) vs the ACN of the oil in various surfactant systems, Dehydol LS3 TH, Dehydol LS5 TH and Dehydol LS7 TH $(10 \% \mathrm{v} / \mathrm{v})$ without salinity

According to Fig. 1, the results showed that the PIT of each surfactant increased with the increasing of the alkane carbon number of oil ( $n$-alkane, C6-C16). The increment of the $\mathrm{ACN}$ required higher temperature for the microemulsion phase inversion from Winsor type I to Winsor type III.

The relative linear graph was used for calculation the ACN regarding the three vegetable oils (soybean oil, crude rice bran oil and crude palm oil). Table 2 shows the PIT of all surfactant-oil systems. According to the linear regression, the ACNs of vegetable oils were $17.60 \pm 0.28,15.41 \pm 0.35$ and $13.71 \pm 0.41$ for soybean oil, crude rice bran oil and crude palm oil, respectively. This was a result of the structure of each oil and the differences in their main fatty acid composition [12].

Table 2. Effect of surfactant types on the phase inversion temperature with three different vegetable oils

\begin{tabular}{lccc}
\hline \multirow{2}{*}{ Surfactants } & \multicolumn{3}{c}{ PIT $\left({ }^{\circ} \mathrm{C}\right)$} \\
\cline { 2 - 4 } & $\begin{array}{c}\text { Soybean } \\
\text { oil }\end{array}$ & $\begin{array}{c}\text { Crude rice } \\
\text { bran oil }\end{array}$ & $\begin{array}{c}\text { Crude } \\
\text { palm oil }\end{array}$ \\
\hline Dehydol LS3 TH & 39 & 36 & 34 \\
Dehydol LS5 TH & 53 & 48 & 45 \\
Dehydol LS7 TH & 65 & 61 & 57 \\
\hline
\end{tabular}

Moreover, at high $\mathrm{ACN}$ of oils, the system requires more free energy (high temperature) for transferring oil molecule from oil phase to microemulsion phase. The effect of $\mathrm{ACN}$ on the microemulsion formations can be seen elsewhere [4].

\subsection{Effect of EON on PIT study}

The effect of EON on PIT was investigated by using a $10 \% \mathrm{v} / \mathrm{v}$ Dehydol LS series with four hydrocarbons. A plot of the phase inversion temperature (PIT) versus the ethylene oxide groups (EON) of the surfactants is shown in Fig. 2.

From Fig.2, the results showed that the PIT of all systems increased with the increasing of the EON of surfactant. The slope of the plot shows a relation between the optimum phase transition temperature and numbers of ethoxylate group. The results showed that the PIT increased, $5.31 \pm 0.72^{\circ} \mathrm{C}$ per one unit of ethylene oxide group. Furthermore, these results are consistent with other researchers $[4,8]$.

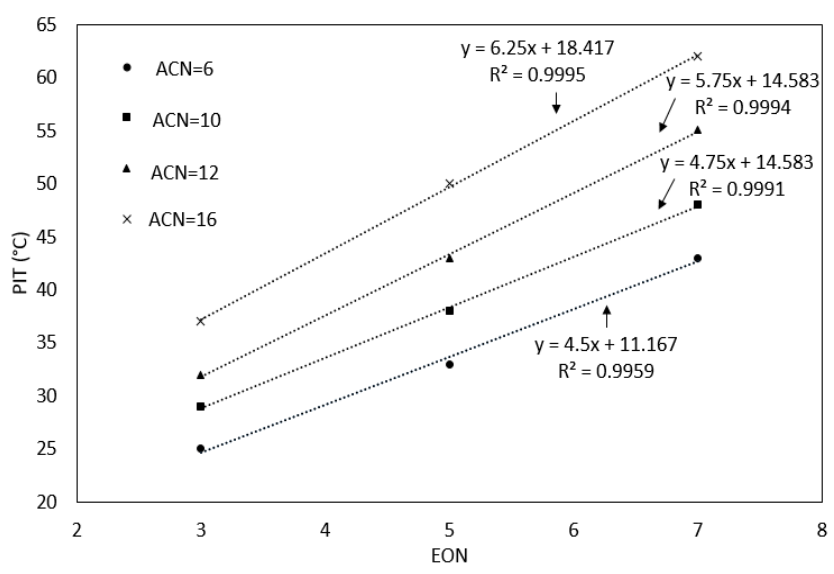

Fig.2 A plot of the phase inversion temperature (PIT) vs the ethylene oxide groups of the surfactant $(\mathrm{EON})$

\subsection{Determination of optimum salinity using HLD}

From the phase inversion temperature (PIT) study, the $\beta$ value of Dehydol LS3 TH, Dehydol LS5 TH and Dehydol LS7 TH were determined to be $1.80,1.09$ and 0.31 , respectively. The $\beta$ values of these surfactants were similar with the reported values of Arpornpong et al. [8].

Fig.3 illustrates the relationship between temperature and optimum salinity. Regarding all the surfactants, the predicted optimum salinities $\left(\mathrm{b}\left(\mathrm{S}^{*}\right)\right)$ from HLD equation (dash trend lines) were found in agreement with the experimental data (solid trend lines) at elevated temperatures.

The decreasing of temperature affects the increment of optimum salinity in the system. The phase transitions were observed from Winsor Type I to III microemulsion (at $\mathrm{HLD}=0$ ) with an increasing temperature parameter $(\Delta T)$ and salinity concentration $(S)$. Arpornpong et al. [8] reported that this slight differences may come from the calculated $\mathrm{ACN}, \beta$, and other environmental parameters 
in the experiment. Thus, it could be summarized that the HLD equation has the ability for guiding the optimum salinity concentration and temperature for a microemulsion formation.

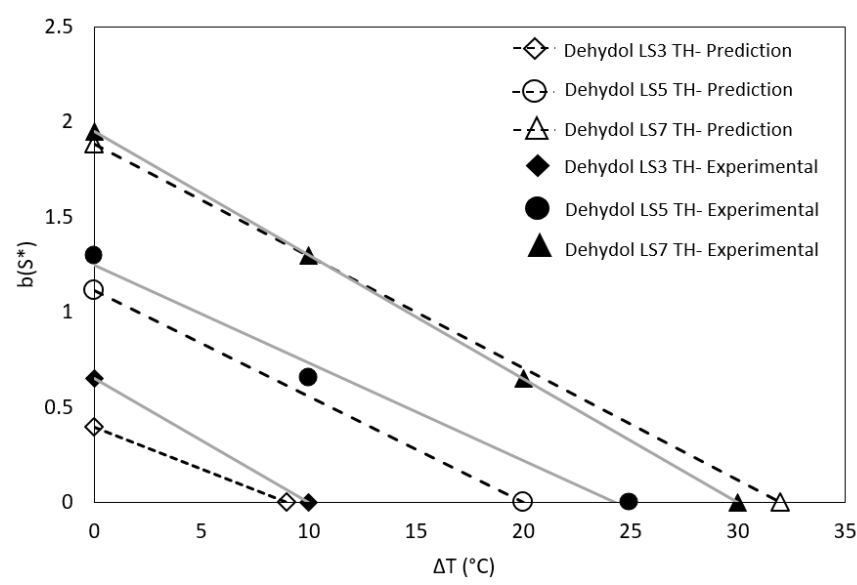

Fig.3 The comparison of optimum salinity $\left(\mathrm{S}^{*}\right)$ obtained by prediction using HLD and the experimental phase behavior study of the system of $2 \% \mathrm{v} / \mathrm{v}$ surfactant solution with crude palm oil

\section{Conclusion}

This study investigated the effect of ethoxylate nonionic surfactants on the phase inversion temperature of a surfactant-vegetable oil system. The ACN of vegetable oil is one of the key parameters in the microemulsion formation, and was thus investigated in this study. The ACNs of soybean oil, crude rice bran oil and crude palm oil were 17.60, 15.41 and 13.71, respectively. The ACN and $\beta$ data calculated in this work were then used in the HLD equation for predicting the optimum salinity and temperature. The result showed that the increase of one EON group of the ethoxylate surfactant increased the phase inversion temperature by $5.31^{\circ} \mathrm{C}$. In comparison, the data regarding these predictions along with the experimental results showed a slight deviation in the optimum salinity. Therefore, the HLD equation has the ability to be used as a guidance for formulating microemulsion-based washing agent, in accordance with the enhancing vegetable oil recovery from spent bleaching earth.

\section{Acknowledgement}

Financial support for this work was provide by the National Research Council of Thailand (NRCT2561004) and the Thailand research fund (MRG6080015). Moreover, the researchers would like to thanks the Surin Bran Oil Co., Ltd., the Suksomboon palm oil Co., Ltd., and the Thai ethoxylate Co., Ltd. for providing us with the materials and chemical compounds to successfully accomplish this research.

\section{References}

1. K. Loh, F. Cheng, M.Choo, N. Ma., J American Applied Sci 3, 2063-2067 (2006)

2. DIW., 3Rs for industrial wastes management. (Ministry of Industry, Bangkok, 2012)

3. M.J. Rosen, Micelle Formation by Surfactants, In Surfactants and Interfacial Phenomena (John Wiley \& Sons Inc., New Jersey, 2004)

4. J.L. Salager, A.M. Forgiarini, B. Johnny, J. Surfact. Deterg. 16, 449-472 (2013)

5. W.H. Wade, J.C. Morgan, R.S. Schechter, J.K. Jacobson, J.L. Salager, Soc. Pet. Eng. 18, 242-252 (1978)

6. J.L. Salager, N. Marquezm A. Graciaa, J. Lacgaise, Langmuir 16,5534-5539 (2000)

7. J.L. Salager, J.C. Morgan, R.S. Schechter, W.H. Wade, E. Vasquez, soc. Pet. Eng. J. 19, 107-115 (1979)

8. N. Arpornpong, A. Charoensaeng, S. Khaodhiar, D. Sabatini, Colloids Surf. A. 541, 87-96 (2018)

9. L. Cash, J.L Cayias, G. Fournier, D. Macaister, T. Schares, E.H. Wade, J. Colloid Interface Sci. 59, 39-44 (1977)

10. M. Bourrel, J.L. Salager, R.S. Schechter, W.H. Wade, J. Colloid Interface Sci. 75, 451-461 (1980)

11. J.L. Salager, L. Manchego, L. Marquez, J. Bullo, A. Forgiarini, J. Surfact. Deterg. 17, 199-213 (2014)

12. A. Witthayapanyanona, E.J. Acosta, J.H. Harwell, D.A. Sabatini, J. Surfact. Deterg. 9, 331-339 (2006) 